Louisiana State University

LSU Digital Commons

Faculty Publications

Department of Biological Sciences

4-1-2015

Drivers of observed biotic homogenization in pine barrens of central wisconsin

Daijiang Li

University of Wisconsin-Madison

Donald Waller

University of Wisconsin-Madison

Follow this and additional works at: https://digitalcommons.Isu.edu/biosci_pubs

Recommended Citation

Li, D., \& Waller, D. (2015). Drivers of observed biotic homogenization in pine barrens of central wisconsin. Ecology, 96 (4), 1030-1041. https://doi.org/10.1890/14-0893.1

This Article is brought to you for free and open access by the Department of Biological Sciences at LSU Digital Commons. It has been accepted for inclusion in Faculty Publications by an authorized administrator of LSU Digital Commons. For more information, please contact ir@lsu.edu. 


\title{
Drivers of observed biotic homogenization in pine barrens of central Wisconsin
}

\author{
DAiJiang Li AND Donald Waller ${ }^{1}$ \\ Department of Botany, University of Wisconsin, Madison, Wisconsin 53706 USA
}

\begin{abstract}
Fire suppression throughout the 20th century greatly altered plant communities in fire-dominated systems across North America. Our ability to assess these effects over the long term, however, is handicapped by the paucity of baseline data. Here, we used detailed baseline data from the 1950s to track changes in the over- and understory composition of pinebarrens vegetation growing on sandy, glacial lake-bed sediments in central Wisconsin. We expected fire suppression to favor succession to closed-canopy conditions, leading to decreases in shade-intolerant and fire-adapted species and consequent reductions in alpha and gamma diversity. We also expected beta diversity to decline due to increases in shade-tolerant, firesensitive, and exotic species. In fact, fire suppression has greatly altered the structure and composition of these pine-barrens communities over the past 54 years. Woody, windpollinated, and shade-tolerant species all increased in richness and abundance, as expected, with succession following fire suppression. Contrary to expectations, local and regional species richness increased by $12 \%$ and $26 \%$, respectively, while Shannon beta diversity declined $24.1 \%$. Increases in canopy coverage and number of native species appear to have driven this biotic homogenization. In contrast, increases in exotic species in our study did not promote biotic homogenization, reflecting their relative rarity across sites. Our findings highlight the key role fire plays in shaping the assembly of these pine-barrens communities.
\end{abstract}

Key words: beta diversity; biotic homogenization; fire regime shift; functional traits; pine barrens; plant community change; resurvey; species losers; species winners; succession; Wisconsin, USA.

\section{INTRODUCTION}

Anthropogenic and natural disturbances profoundly affect biodiversity and ecosystem functions (Naeem et al. 2009). Understanding how these disturbances affect plant communities can inform efforts to conserve ecosystem taxonomic and functional diversity, manage plant communities, and anticipate how plant communities will respond to changing disturbance regimes. Fire, an important and common form of disturbance, can strongly influence plant community structure and composition (Bond et al. 2005, Bond and Keeley 2005, Bowman et al. 2009). As a corollary, the absence of fire can also strongly shape plant community structure and composition. Fire suppression in North America began around 1905 (Appendix A: Fig. A1), bringing many such effects. Fire suppression can also shift plant communities into alternative stable states (Nowacki and Abrams 2008). However, the full nature and extent of the effects of fire suppression on long-term dynamics of plant communities often remain unclear, reflecting a dearth of baseline data.

A few long-term plant community studies confirm that fire profoundly affects plant community structure and composition. Prairies, for example, quickly suffer

Manuscript received 11 May 2014; revised 5 September 2014; accepted 15 September 2014. Corresponding Editor: G. A. Fox

${ }^{1}$ Corresponding author. E-mail: dmwaller@wisc.edu woody plant encroachment and native species losses when fires do not occur (Leach and Givnish 1996). Studies of fire effects on forests tend to focus on changes in overstory. Excluding fire usually increases the species richness, density, and basal area of trees (Parsons and DeBenedetti 1979, Peterson and Reich 2001, Collins et al. 2011, Dolanc et al. 2014), as expected with succession (Veno 1976). Such succession substantially shifts tree species composition in both temperate (Gilliam and Platt 1999, Peterson and Reich 2008) and tropical forests (Barlow and Peres 2008).

The effects of fire and fire suppression on understory plant communities are less well known (Nowacki and Abrams 2008). In several studies, understory species diversity decreased in the absence of fire (Brockway and Lewis 1997, Peterson and Reich 2008, Knapp et al. 2013). Other studies, however, show a different pattern. For example, Woinarski et al. (2004) found no differences in species diversity between burned and unburned treatments in a Eucalyptus forest in northern Australia. Determining the impact of fire on understory plant communities is critical for understanding patterns of biodiversity and ecosystem function, as understory species comprise up to $80 \%$ of forest taxonomic diversity and contribute disproportionally to ecosystem services, like nutrient cycling (Nilsson and Wardle 2005).

The central sand plains (CSP; Fig. 1) in Wisconsin, USA is a favorable region to study the longer-term 


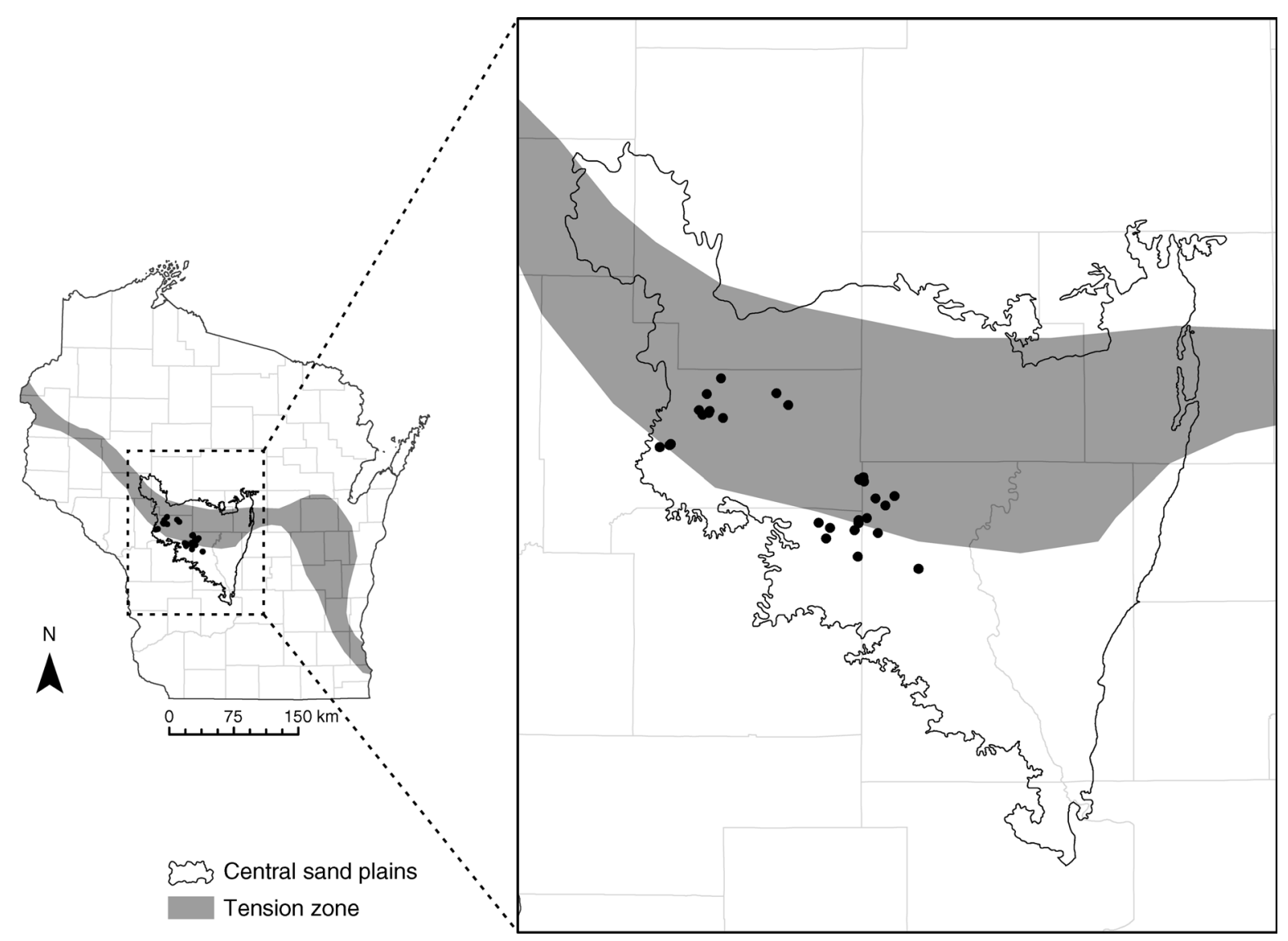

FIG. 1. Map of the 30 study sites in the central sand plains of Wisconsin, USA.

effects of fire suppression on plant communities. During presettlement times, fire was very common in the CSP (Curtis 1959, Wisconsin Department of Natural Resources 2014). After the 1930s, fire frequency in the CSP declined due to extensive fire suppression, land use changes, and habitat fragmentation. In the Midwest, fire exclusion commonly causes a shift to more mesic, latersuccessional canopy species (Wisconsin Department of Natural Resources 2014). Such species usually tolerate shade, but not fire, causing a shift in composition that is sometimes labeled "mesification" or "mesophication" (Nowacki and Abrams 2008). Without fire, abandoned agricultural fields, savannas, and prairies in the CSP became forest within 30 years (Thomson 1943, Habeck 1959a).

To characterize long-term changes in the over- and understory of plant communities following fire suppression, we resampled 30 sites in the western part of the CSP that had been originally sampled by Habeck (1959a). Until 1958, most of these sites were open upland sand plain forests, composed mostly of jack pine and northern pin oak, with an average canopy cover of $55 \%$ (Habeck 1959a). Given extensive fire suppression in the CSP, we expected these plant communities to shift in both structure and composition. Specifically, we made the following three hypotheses. First, we expected fire suppression to have favored succession towards more mesic plant communities. In overstory, we expected increases in canopy closure, average tree basal area, and shade-adapted species such as white pine, and decreases in tree density and fire-adapted species such as jack pine. In the understory, we expected the number and abundance of shade-tolerant and woody and graminoid species to increase, and species adapted to fire and more xeric, open conditions to decrease. Second, we expected understory local species diversity $(\alpha)$ and regional diversity $(\gamma)$ to have decreased in response to fire suppression. Finally, we expected understory species composition to have converged among sites (i.e., biotic homogenization) because of increasing exotic species and canopy coverage.

\section{Methods}

\section{Study sites and area}

The CSP covers 885800 ha, representing $6.1 \%$ of the land area of the Wisconsin state. This area represents the bed of Glacial Lake Wisconsin overlying sandstone bedrock. Remarkably flat sand plains dominate this area, with occasional sandstone and quartzite hills rising up to $61 \mathrm{~m}$ above the plain (Wisconsin Department of 
Natural Resources 2014). The current annual mean temperature is $6.6^{\circ} \mathrm{C}$, mean annual precipitation is 833 $\mathrm{mm}$. The mean growing season is 135 days, which is 19 days less than the average for southern Wisconsin. The soils are very sandy and well-drained, limiting water availability and favoring xeric species like northern pin oak (Quercus ellipsoidalis) and jack pine (Pinus banksiana; see Plate 1). These species produce acidic leaf litter that decomposes slowly and accumulates on the ground, which limits available nutrients and, ultimately, favors fire. Burning causes considerable nitrogen loss through volatilization, erosion of ash, and leaching (Debano and Conrad 1978). This further favored species adapted to fires as well as low nutrients and kept these habitats fairly open.

Although large wetland complexes, sand prairies, oak forests, and barrens dominated the CSP prior to European settlement, land use has changed greatly since then. Agricultural efforts focused on lowland sites, with many marshes drained for cropland between 1880 and 1920. Nearly all these efforts were abandoned by the late 1930s, due to low soil fertility (Thomson 1943, Habeck $1959 a$ ) and summer frosts in low-lying areas. It is likely that none of our study sites supported agricultural activities before the 1930s, as they are sandy upland sites (James Habeck, personal communication).

We resampled sites in the western part of the CSP (Fig. 1). In the 1950s, these sites mostly were firemaintained barrens, characterized by open sand-plains dominated by jack pine and northern pin oak and containing few mesic species, such as red pine (Pinus resinosa) or red maple (Acer rubrum, Habeck 1959a). Jack-pine openings in this area burned at an interval of 22-27 years before European settlement (Simard and Blank 1982). Since the 1930s, however, fires have been largely suppressed. Although the exact fire history of our sites is unknown, Habeck noted no evidence of recent burning at these sites in 1958. In our field work and discussions with land managers and owners, we also noted a lack of evidence for subsequent fires at these sites.

\section{Vegetation sampling}

Between June and August of 1958, Habeck (1959a) sampled 40 sites that he found free of recent disturbance in the western CSP using the point-quarter method (Cottam and Curtis 1956). He sampled 20 points at each site, providing samples of 80 trees, 80 saplings, 80 shrubs, and $201-\mathrm{m}^{2}$ quadrats for each site. Within each quadrat, he recorded the presence or absence of all vascular plant species and measured canopy coverage using a densiometer. In addition, he recorded townshiprange-section (TRS) information and sometimes made hand-drawn maps, but did not mark permanent site locations. His goal was to understand how plant species in these communities respond to continua in environmental conditions and winter deer browsing.
During the summer of 2012, we used the TRS information and maps to relocate each of Habeck's sites. We then used Bordner's (1934) vegetation survey maps and Habeck's (1959a) data on original plant composition to select the most likely location. This usually brought us to within $200 \mathrm{~m}$ of the original survey location. We disqualified 10 of the original 40 sites as five had recently been logged, four could not be relocated, and one was too small now.

Within each of the 30 relocated sites (Fig. 1), we sampled a homogeneous area (consistent with Habeck 1959a) during the same season as Habeck did (June to August). We adapted protocols for long-term monitoring developed by Johnson and Waller (2012), seeking to mimic Habeck's original sampling methods, but expanding sampling effort for understory plants in order to provide a better distribution of sampling effort among forest layers.

At each site, we laid out five parallel, $50 \mathrm{~m}$ long transects, spaced $20 \mathrm{~m}$ apart, starting from a randomly chosen initial point. To avoid edge effects, we sampled at least $30 \mathrm{~m}$ from any forest edge. For woody plants, we constructed three $10 \times 50 \mathrm{~m}$ sampling plots by sampling $5 \mathrm{~m}$ to both sides of the first, third, and fifth transects (total sample area of $1500 \mathrm{~m}^{2}$ ). Within these plots, we recorded the identity and diameter at breast height (dbh) of all trees (defined as having a dbh $>10.16 \mathrm{~cm}$ ) and the identity and number of saplings $(2.5 \mathrm{~cm}<\mathrm{dbh}<10.16$ $\mathrm{cm})$. We then recorded presence of all vascular plants in each of $501-\mathrm{m}^{2}$ quadrats spaced every $5 \mathrm{~m}$ along all five transects. We took six vertical fish-eye photographic images at each site to estimate canopy coverage. Finally, we noted the presence of obvious disturbances (e.g., logging, trails).

Any plant not identified to species in the field was collected and later identified in the lab with expert taxonomic assistance. We lumped species into their genus when we had only genus names in the 1958 data and on the few occasions when the accuracy of identification was still in doubt after consulting with specialists (e.g., some Carex, Viola, and Rubus). We synchronized the taxonomy between surveys before conducting analysis following the Wisconsin State Herbarium's flora list $^{2}$ and identified species as exotic if their status in the Wisconsin State Herbarium flora list was introduced.

\section{Statistical analysis}

Changes in community structures.-To test our hypothesis about successional changes in overstory (i.e., increasing canopy coverage, tree $\mathrm{dbh}$, and shadetolerant species; decreasing tree density and fire-adapted species), we estimated canopy coverage, tree density (stems per hectare), mean dbh per stem, and total basal area per hectare (BA/ha) for each site in both 1958 and

\footnotetext{
${ }^{2}$ http://botany.wisc.edu/wisflora/
} 


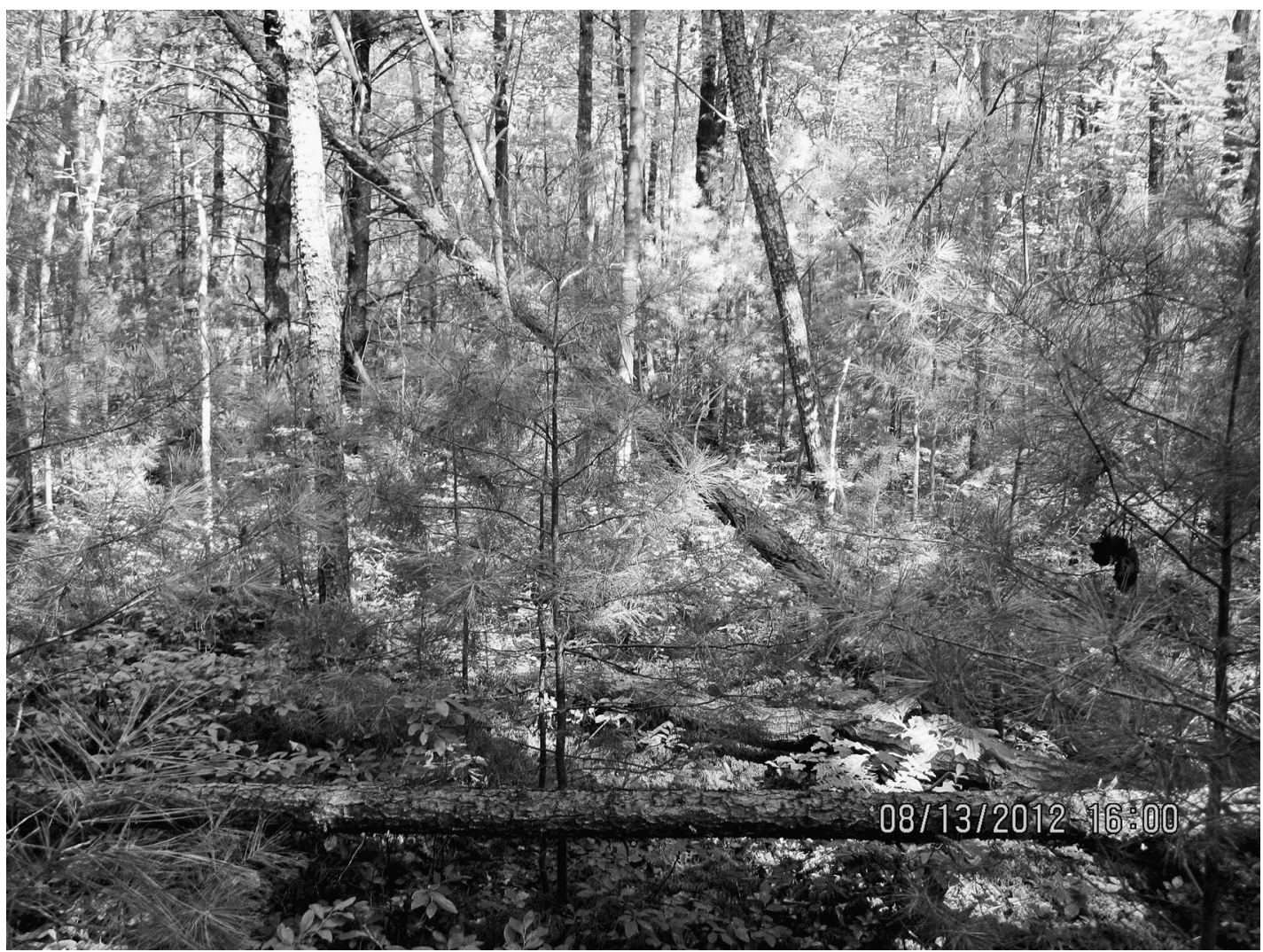

Plate 1. A typical view at one of our study sites in 2012. The downed and leaning trees are mostly senescent jack pine (Pinus banksiana) and northern pin oak (Quercus ellipsoidalis), while the regenerating trees are primarily white pine (Pinus strobus). The location of this site is $44.3453055556^{\circ} \mathrm{N}, 90.7453333333^{\circ} \mathrm{W}$. Photo credit: D. Li.

2012. We used paired $t$ tests to explore differences in overstory structure between two time periods. Density and BA/ha estimates from the 1950s implicitly assume that trees are distributed randomly. Clumped or overdispersed distributions would lead to some bias. We also calculated importance value (Curtis 1959) for each tree species at each time period. The importance value (IV) of a tree species is the mean of its relative abundance (number of stems for that species/total number of stems observed), its relative frequency (number of sites observed for that species/sum of number of sites observed for all species), and its relative basal area (basal area of that species/total basal area for all species) across all sites. We plotted the distributions of IV and dbh values of major canopy species across sites for each time period to qualitatively assess their dynamics.

To test the successional hypothesis among understory species (i.e., increasing woody, fern, graminoid, and shade-tolerant species; decreasing forbs and fire-adapted species), we compared the frequency of these different plant groups between time periods. We also identified winners (species that increased significantly) and losers (species that decreased significantly) in our dataset, using indicator species analysis (ISA; Dufrene and
Legendre 1997). To ensure biological and statistical significance, we limited our analysis to species present in at least three sites and 10 quadrats sampled in either sampling period. We classify significant $(P<0.05$, permutation test) indicator species of 1958 as losers, significant indicator species of 2012 as winners, and the rest as no change (cf. McCune and Vellend 2013).

To understand why particular species increased or decreased, we compared functional traits for understory winners and losers. As environmental changes become stronger and more pervasive, we expect species adapted to these changes to increase, while those not adapted to decrease. We, therefore, explored whether species in each of these groups shared particular functional traits, assuming that such traits could inform our knowledge of the factors driving community change. We extracted selected functional trait data for species used in the ISA $(n=80$ species $)$ from a broader trait database for Wisconsin species (Wiegmann and Waller 2006, Amatangelo et al. 2014, Sonnier et al. 2014). The traits include growth habit (forb, fern, fern allies, graminoid, and woody), shade tolerance (intolerant, intermediate, and tolerant), pollination mode (abiotic and biotic), seed dispersion mode (animal, wind, ant, and unassisted), 


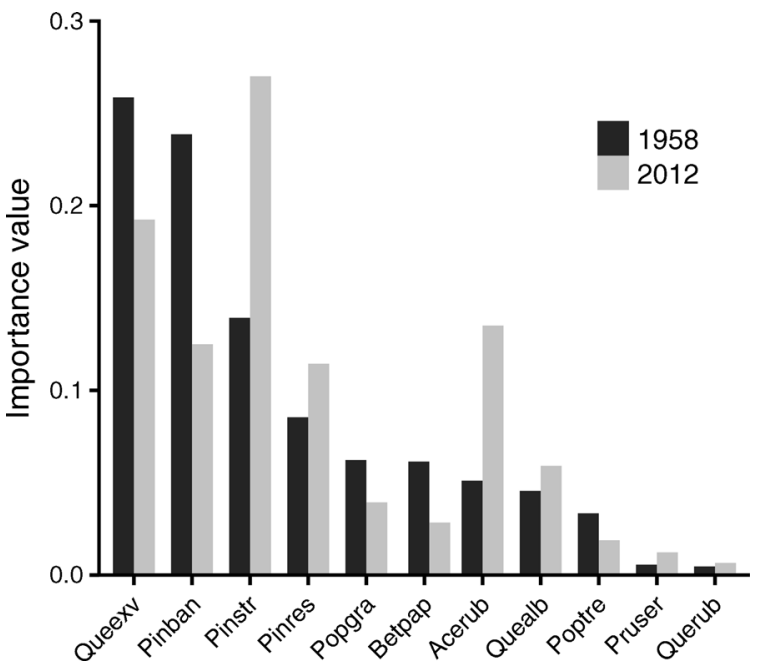

FIG. 2. Changes in relative abundance of major canopy trees from 1958 to 2012 in 30 pine barrens sites in central Wisconsin. The importance value of a tree species is its mean relative abundance (number of stems for that species/total number of stems observed), its relative frequency (number of sites observed for that species/total sites observed for all species), and its relative basal area (basal area of that species/ total basal area for all species) across all sites. Species abbreviations are: Queexv, Quercus ellipsoidalis or Quercus velutina; Pinban, Pinus banksiana; Pinstr, Pinus strobus; Pinres, Pinus resinosa; Popgra, Populus grandidentata; Betpap, Betula papyrifera; Acerub, Acer rubrum; Quealb, Quercus alba; Poptre, Populus tremuloides; Pruser, Prunus serotina; Querub, Quercus rubra.

seed mass ( $\mathrm{g} / 1000$ seeds), species origin (native and exotic), distribution range (Wisconsin-centroid, S-centroid, and $\mathrm{N}$-centroid), life cycle (annual, biennial, and perennial), specific leaf area (SLA; $\mathrm{cm}^{2} / \mathrm{g}$ ) and leaf dry matter content (LDMC; $\mathrm{mg} / \mathrm{g}$ ). We chose functional traits that we felt were related to potential drivers of plant community changes in our sites (e.g., species invasion, succession, or climate change). To test whether the winner, loser, and no change species groups differed in each trait, we applied ordinal logistic regression with species indicator status as the dependent variable and trait as a predictor (simple regression). To assess the significance of these associations, we compared models with the trait value to models with only the intercept using likelihood ratio tests.

Changes in local and regional species diversity.-To test our second hypothesis, that local and regional diversity have decreased, we estimated species diversity in each site and at each time period. Because sampling efforts differ between time periods ( 80 trees per site in 1958 vs. between 42 and 121 in 2012; and 20 understory quadrats per site in 1958 vs. 50 in 2012), we used rarefaction to standardize sampling effort (Gotelli and Colwell 2001). For the overstory data, we applied individual-based rarefaction (Gotelli and Colwell 2001) by randomly sampling 42 trees (the minimum number of trees per site) without replacement 1000 times. For the understory data, we applied sample-based rarefaction (Gotelli and Colwell 2001) by randomly sampling 20 quadrats without replacement 1000 times. For each iteration, we calculated the value of each diversity metric (discussed below), and then used the mean of these 1000 values as our estimate of the diversity metric for a given site when rarefaction was needed. In the overstory, we calculated species richness for each site because there are few tree species in our sites. As higher diversity is found in the understory, we used additional diversity metrics to characterize the understory data. We estimated mean species, native species, and exotic species richness; the exponential of Shannon entropy $\left(H^{\prime}=\exp (H)\right.$, termed here Shannon diversity); the inverse Simpson concentration $(1 / S$, termed here Simpson diversity); and mean species richness of the plant groups (forbs, graminoids, ferns, fern allies, and woody) at both the site level (20 $\left.\mathrm{m}^{2}\right)$ and the quadrat level $\left(1 \mathrm{~m}^{2}\right)$ for each site. Species richness, $H^{\prime}$, and $1 / S$ represent the first three Hill numbers all in units of number of species, facilitating comparisons among sites and measures (Jost 2007). To test the difference between time periods in these diversity estimates, we used paired $t$ tests. In cases where the residuals did not meet the normality assumption, we used paired Wilcoxon signed-rank tests.

We also calculated the mean number of understory species gained, lost, and persisting at each site using rarefied data to better understand species diversity dynamics. We estimated the rate of species turnover at each site as

$$
1-\frac{S_{1958 \cap 2012}}{\left(S_{1958}+S_{2012}\right) / 2}
$$

where $S_{1958}$ and $S_{2012}$ are the species richness of 1958 and 2012 at that site, respectively, and $S_{1958 \cap 2012}$ is the number of species found at both date at that site.

Changes in understory species composition.-To test whether understory composition of these sites has become more homogeneous, we used a corrected Shannon beta diversity index (Jost 2007), non-metric multidimensional scaling (NMDS), and a distance-based test for homogeneity of multivariate dispersion (PERMDISP; Anderson et al. 2006). These methods apply different, but complementary, approaches to measure variability in species composition among sites. When all three give similar results, we can have more confidence.

Jost's (2007) beta diversity measure represents a multiplicative decomposition of Shannon diversity, i.e., $\beta H^{\prime}=\gamma H^{\prime} / \alpha H^{\prime}$. This measure is fully independent of alpha diversity, thus comparable across studies and regions. With biotic homogenization, we expect decreases in beta diversity.

NMDS was conducted to ordinate understory species composition of all sites in 1958 and 2012 using the BrayCurtis dissimilarity measure $\left(d_{\mathrm{BC}}\right)$ and the Wisconsin transformation (species first standardized by species maximum then sites by site total). We linked points 
TABLE 1. Changes in percentage of quadrats occupied (mean \pm SD) by different plant groups in the understory of sand plain sites in central Wisconsin, USA from 1958 to 2012, using the Wilcoxon signed-rank test.

\begin{tabular}{lcrr}
\hline \hline & \multicolumn{2}{c}{ Relative quadrat frequency (\%) } & \\
\cline { 2 - 3 } Plant characteristic & \multicolumn{1}{c}{1958} & 2012 & \multicolumn{1}{c}{$P$} \\
\hline Plant growth habit & & & \\
$\quad$ Forb & $46.1 \pm 8.3$ & $28.4 \pm 6.6 \downarrow$ & $<0.0001$ \\
$\quad$ Fern and fern ally & $0.4 \pm 0.8$ & $1.7 \pm 2.0 \uparrow$ & 0.0004 \\
$\quad$ Graminoid & $6.5 \pm 10.0$ & $12.4 \pm 6.9 \uparrow$ & 0.0058 \\
$\quad$ Woody & $46.7 \pm 11.0$ & $57.4 \pm 5.9 \uparrow$ & $<0.0001$ \\
Plant origin & & & \\
$\quad$ Exotic & $0.7 \pm 2.6$ & $1.7 \pm 3.3 \uparrow$ & 0.061 \\
$\quad$ Native & $99.3 \pm 2.6$ & $98.3 \pm 3.3 \downarrow$ & 0.061 \\
\hline
\end{tabular}

Notes: Up arrows indicate increases since 1958; down arrows indicate decreases since 1958 . There are 20 quadrats per site in both 1958 and 2012.

representing the same site sampled in different years using vectors. The length and direction of these vectors allow us to compare the direction and magnitude of the changes in community composition across sites. To assess whether understory species composition changed significantly over time, we applied permutational multivariate ANOVA (PERMANOVA).

For the PERMDISP method, we followed Anderson et al.'s (2006) recommendation, using various dissimilarity measures and data transformations, including the Jaccard dissimilarity measure $\left(d_{\mathbf{J}}\right)$ with presence or absence (1 or 0) data, Sørensen dissimilarity measure $\left(d_{\mathrm{S}}\right)$ with presence or absence (1 or 0$)$ data, Gower's modified dissimilarity measure $\left(d_{\mathrm{MG}}\right)$ with $\log _{10}(x+1)$ transformation for positive values, and $d_{\mathrm{BC}}$ with the Wisconsin data transformation.

To study possible predictors of changes in site similarity, we first calculated the centroid of all sites from both time periods in multivariate species-space using PERMDISP ( $n=60$ sites, $d_{\mathrm{BC}}$ with Wisconsin transformation). For each site, we then subtracted the distance to the centroid in 2012 from the distance observed in 1958 to calculate changes in distance. Positive values mean that the site has moved to the centroid, contributing to homogeneity (McCune and Vellend 2013). Lastly, we regressed changes in distance across sites with net changes in exotic species richness (at both site- and quadrat-level), native species richness (at both site and quadrat level), and canopy coverage to identify possible predictors of biotic homogenization.

All analyses were carried out in R v3.0.0 ( $\mathrm{R}$ Core Team 2013), using the vegan package (Oksanen et al. 2013) for the multivariate analyses, the labdsv package (Roberts 2013) for ISA, and the ordinal package (Christensen 2013) for the ordinal logistic regression.

\section{RESUlts}

\section{Changes in community structures}

Over the past 54 years, tree density has decreased $24 \%$ (from 724 to 550 trees/ha; paired $t_{29}=-3.31, P=0.003$ ) while the average dbh per stem has increased $15 \%$ (from 19 to $22 \mathrm{~cm} /$ tree; paired $\left.t_{29}=3.94, P=0.0004\right)$. Although estimated stand basal area only increased $7 \%$ (from 22.57 to $24.18 \mathrm{~m}^{2} /$ ha; paired $t_{29}=0.78, P=0.44$ ), canopy cover increased $59 \%$ (from 55.01 to $87.33 \%$; paired $\left.t_{29}=8.99, P<0.0001\right)$. The abundance of midstage successional species, such as Acer rubrum, Pinus resinosa, and Pinus strobus, all increased, while early successional species, such as Betula papyrifera, Pinus banksiana, Populus grandidentata, Quercus velutina, and Quercus ellipsoidalis, all declined (Fig. 2; see Plate 1). Among understory species, the relative abundance of forbs decreased, while fern, graminoid, and woody plants all increased (Table 1).

Of the 80 species present in at least three sites and 10 quadrats, we identified 8 losers, 43 that did not change much in abundance, and 29 winners (Appendix A: Table A1). The losers are all early-successional (e.g., prairie and open area) species, including Houstonia longifolia, Lupinus perennis, Helianthemum canadense, Krigia biflora, Achillea millefolium, Aster sagittifolius, and Antennaria spp. Plant growth habit, pollination mode, and shade tolerance all varied among these groups (Table 2, Fig. 3). Most winners were ferns, graminoids, or woody species, while most losers were forbs (Fig. 3a).

TABLE 2. Results of association between indicator status of sand plain understory species (losers, no change, and winners) and their functional traits using ordinal logistic regression.

\begin{tabular}{|c|c|c|c|}
\hline Trait & LRT & $P$ & No. species \\
\hline Growth habit (forb, fern or fern ally, graminoid, woody) & 10.7793 & 0.013 & 80 \\
\hline Shade tolerance (intolerant, intermediate, tolerant) & 10.252 & 0.006 & 80 \\
\hline Pollination mode (abiotic or biotic) & 5.4684 & 0.020 & 79 \\
\hline Dispersal mode (animal, wind, ant, unassisted) & 2.7771 & 0.427 & 77 \\
\hline Seed mass (g/1000 seeds) & 2.2348 & 0.135 & 67 \\
\hline Origin (exotic or native) & 1.3440 & 0.246 & 80 \\
\hline Median of latitude (Southern United States, Wisconsin-centroid, and Canada) & 0.8709 & 0.647 & 80 \\
\hline Life cycle (annual or perennial) & 0.2178 & 0.641 & 80 \\
\hline Specific leaf area, SLA $\left(\mathrm{cm}^{2} / \mathrm{g}\right)$ & 0.1957 & 0.658 & 61 \\
\hline Leaf dry mass content, LDMC $(\mathrm{mg} / \mathrm{g})$ & 0.1257 & 0.723 & 61 \\
\hline
\end{tabular}

Notes: Values in the likelihood ratio test (LRT) column are results from comparison between the full model (fitted with intercept and trait in the same row) and the reduced model (fitted with intercept only). Results in bold indicate significance. 

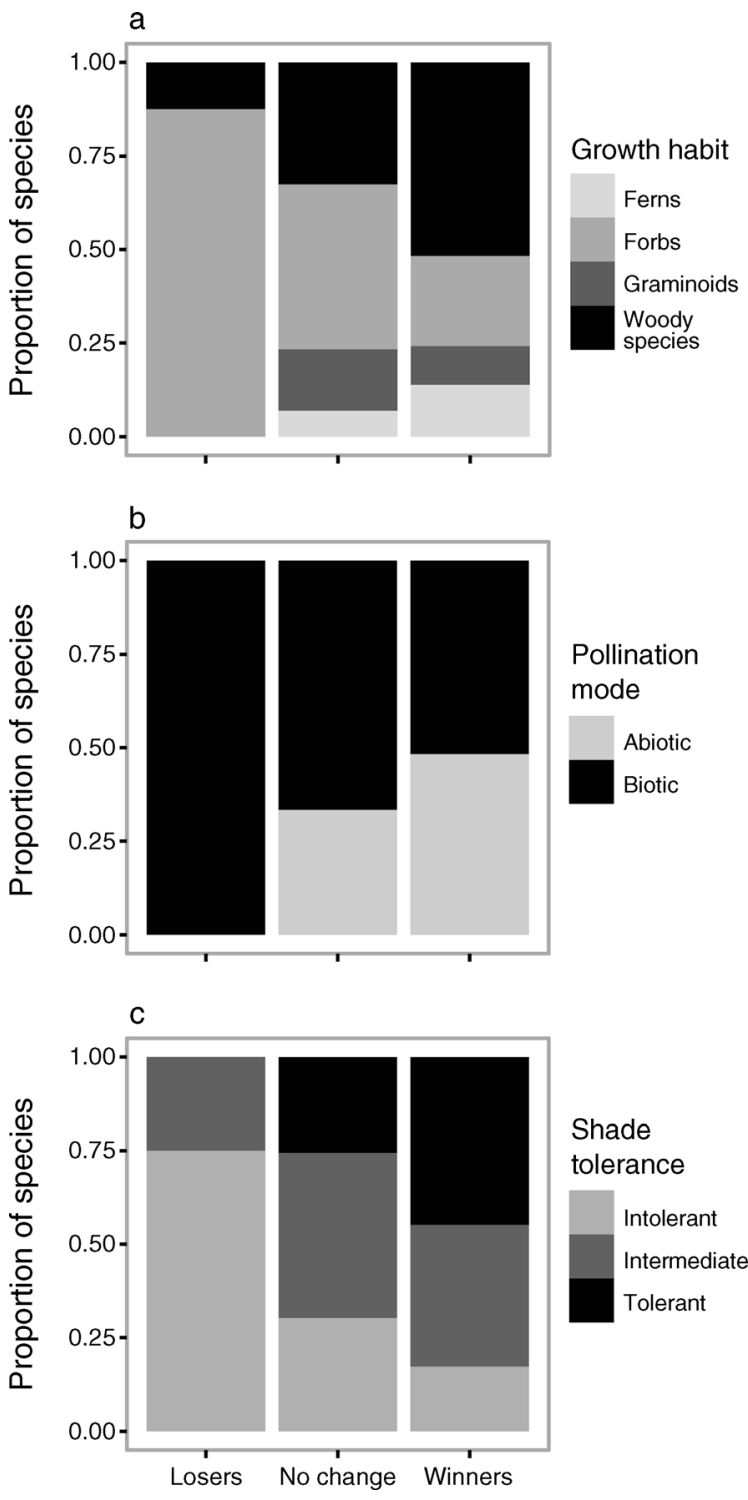

FIG. 3. Proportion of understory species in each category of functional traits that were strongly associated with indicator status: (a) growth habit, (b) pollination mode, and (c) shade tolerance. Sample size was $n=8$ loser species, $n=43$ species with no change, and $n=29$ winner species. Winners and losers are species that have increased or decreased, respectively, in abundance since 1958. No change refers to species that have not changed significantly in abundance since 1958 .

Winners were far more likely to be abiotically pollinated (Fig. 3b) and shade-tolerant (Fig. 3c).

\section{Changes in local and regional species diversity}

The total number of understory species recorded from these sites increased from 105 in 1958 to 159 (no rarefaction, or 132 with rarefaction) in 2012. Following rarefaction, we estimated that 35.4 species were only present in 1958, 69.6 species in both time periods, and 62.2 species only in 2012. In 1958, we observed only two exotic species (Poa pratensis and Hieracium aurantia- cum) that, together, occurred at four sites $(13.3 \%$ of the sites). However, in 2012 (no rarefaction), we found 12 exotic species that, together, occurred in 15 sites $(50 \%$ of the sites).

After rarefaction, average canopy tree species richness increased $29 \%$ (from 4.14 to 5.33 species per site, paired $\left.t_{29}=4.13, P=0.0003\right)$. In the understory, total species, exotic species, and native species richness all increased, along with the Simpson and Shannon diversity measures. All five of these changes were significant at the quadrat level (Table 3). At the site level, one change was significant and two were almost significant (at $P<0.10$, Table 3). As predicted, the number of forb species per site decreased significantly while the number of woody plants, ferns, fern allies, and graminoid plant species increased (Table 3).

In the understory, each site gained more species than it lost, with a mean gain of $14.0 \pm 6.44$ species and a mean loss of $11.7 \pm 5.34$ species. For each site, an average of $11.4 \pm 3.70$ species was present in both periods. This resulted in high turnover rates (mean $52.9 \%$ ), with 16 of the 30 sites experiencing turnover rates $>50 \%$. Sites that increased more in canopy cover experienced higher turnover in their understories $\left(F_{1,28}=\right.$ 11.29, $P=0.002, R^{2}=0.29$ ).

\section{Changes in understory species composition}

Although both local and regional diversity increased, the understory Shannon beta diversity decreased by $24.1 \%$, from 2.39 to 1.81 communities.

We found strong evidence of biotic homogenization among these understory communities in the NMDS ordination (Fig. 4). The permutation MANOVA test showed that plant communities in 1958 and in 2012 significantly differ from each other $\left(F_{1,58}=21.07, P=\right.$ 0.001). The consistent directional changes at most sites in understory communities correlated significantly with local increases in canopy coverage.

The PERMDISP also gave similar results for all metrics (Table 4). Twenty-two of these 30 sites moved toward the centroid of the species-space. Sites that tended to move towards the centroid showed increases in canopy closure $\left(F_{1,28}=14.02, P<0.001, R^{2}=0.334\right.$; Fig. 5a). Increases in native species richness at the quadrat level were larger in communities that have converged more in composition $\left(F_{1,28}=6.077, P=0.02\right.$, $R^{2}=0.178$; Fig. 5 b). After grouping native species based upon their growth habit, we found that increases in woody species richness contributed the most to the positive relationship between increasing native species richness and biotic homogenization. However, convergence in species composition is not correlated with changes in native species richness at the site level $\left(F_{1,28}=\right.$ $\left.0.488, P=0.49, R^{2}=0.017\right)$. Contrary to what we expected, we found no evidence that invasions of exotic species into these sites promoted biotic homogenization at either the site level or the quadrat level (Appendix A: Fig. A5). 
TABLE 3. Changes in understory species diversity of plant communities in the central sand plains of Wisconsin.

\begin{tabular}{|c|c|c|c|c|c|c|c|c|}
\hline \multirow[b]{2}{*}{ Parameters } & \multicolumn{4}{|c|}{ Site-level $\left(20 \times 1 \mathrm{~m}^{2}\right)$} & \multicolumn{4}{|c|}{ Quadrat-level $\left(1 \mathrm{~m}^{2}\right)$} \\
\hline & 1958 & 2012 & $t$ & $P$ & 1958 & 2012 & $t$ & $P$ \\
\hline Total species richness & 23.07 & 25.83 & 1.79 & 0.084 & 5.96 & 6.93 & 2.62 & 0.014 \\
\hline Number of exotic species & 0.13 & 0.52 & $124^{\dagger}$ & 0.025 & 0.13 & 0.60 & $74.5^{\dagger}$ & 0.036 \\
\hline Number of native species & 22.03 & 24.67 & 1.86 & 0.072 & 5.66 & 6.65 & 2.76 & 0.009 \\
\hline Simpson diversity & 12.30 & 13.20 & 1.06 & 0.298 & 5.90 & 6.70 & 2.23 & 0.033 \\
\hline Shannon diversity & 15.69 & 16.79 & 1.02 & 0.316 & 5.92 & 6.75 & 2.99 & 0.006 \\
\hline Number of forb species & 12.00 & 9.74 & -2.64 & 0.013 & 2.93 & 2.01 & -4.85 & $<0.001$ \\
\hline Number of woody plant species & 9.27 & 12.12 & 1.33 & $<\mathbf{0 . 0 0 1}$ & 2.83 & 3.86 & 5.18 & $<\mathbf{0 . 0 0 1}$ \\
\hline Number of fern or fern allies & 0.30 & 0.98 & $31^{\dagger}$ & $<\mathbf{0 . 0 0 1}$ & 0.30 & 0.13 & $159^{\dagger}$ & 0.298 \\
\hline Number of graminoid species & 1.40 & 2.36 & $91^{\dagger}$ & 0.019 & 0.79 & 0.78 & $240.5^{\dagger}$ & 0.877 \\
\hline
\end{tabular}

Notes: Values in 2012 were calculated after rarefaction; $P$ values were calculated from either paired $t$ test or Wilcoxon signedrank test, with $\mathrm{df}=29$. Results in bold indicate significance

$\dagger$ Here, values of $v$, instead of $t$, are reported.

\section{DisCUSSION}

In this study, we documented dramatic changes in the structure and composition of pine-barrens plant communities in central Wisconsin over the past 54 years. Although both alpha and gamma richness increased over this period, the composition of these communities has converged, demonstrating conspicuous biotic homogenization. Surprisingly, we found no evidence that increasing exotic species richness contributed to biotic homogenization. Instead, we found that increases in canopy coverage and shade-tolerant native species following fire suppression drove most of this biotic homogenization.

The increases in alpha and gamma diversity that we observed contrast with results from other long-term studies where alpha diversity declined (Leach and Givnish 1996, Rooney et al. 2004, Rogers et al. 2008, Damschen et al. 2010). Such results have led many to assume that alpha diversity is decreasing in response to global environmental change. Our results, together with other recent work, show that, at regional and local scales, diversity can also increase (Sax and Gaines 2003,

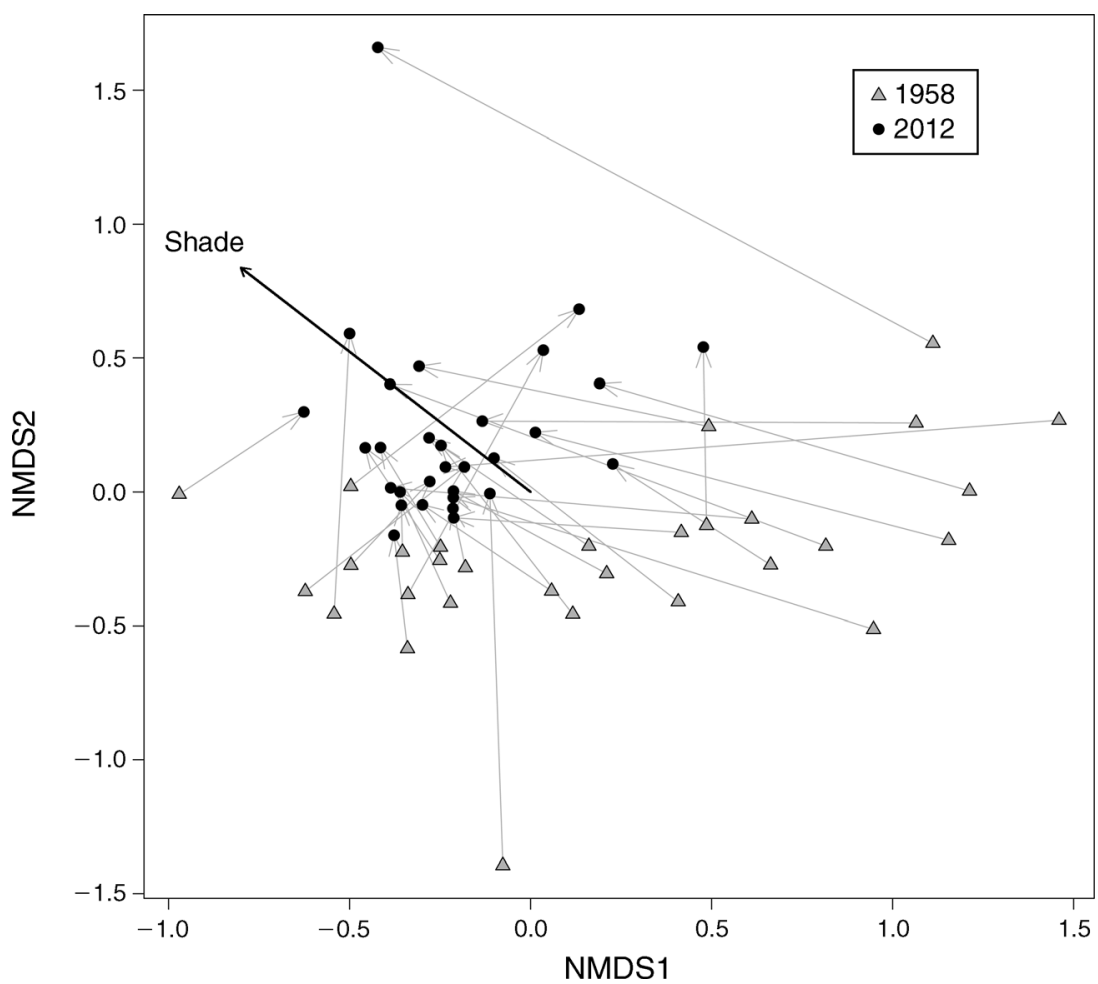

FIG. 4. Nonmetric multidimensional scaling (NMDS) ordination illustrated consistent changes (arrows connecting symbols) in understory species composition of 30 central Wisconsin sites from 1958 to 2012. The shade vector represents the direction of most rapid increase in canopy shade. Changes in species composition among sites were highly correlated with increasing canopy shade $\left(R^{2}=0.637\right)$ 
TABLE 4. Results of permutation tests ( $n=999$ tests) for changes in average distance to species space centroids $(\tilde{z})$ of understories for each time period in central Wisconsin, where decreasing $\tilde{z}$ suggests decreasing variation in species composition (biotic homogenization).

\begin{tabular}{lcccc}
\hline \hline $\begin{array}{l}\text { Dissimilarity measure } \\
\text { (data transformation) }\end{array}$ & $\tilde{z}_{1958}$ & $\tilde{z}_{2012}$ & $F_{1,58}$ & $P$ \\
\hline$d_{\mathrm{J}}(1 / 0)$ & 0.4835 & $0.4158 \downarrow$ & 11.890 & 0.001 \\
$d_{\mathrm{S}}(1 / 0)$ & 0.3797 & $0.3017 \downarrow$ & 12.464 & 0.002 \\
$d_{\mathrm{MG}}\left(\log _{10}[x]+1\right)$ & 0.7471 & $0.6888 \downarrow$ & 3.4995 & 0.065 \\
$d_{\mathrm{BC}}($ Wisconsin) & 0.5372 & $0.4458 \downarrow$ & 16.356 & 0.001 \\
\hline
\end{tabular}

Notes: The dissimilarity terms are Jaccard dissimilarity measure $\left(d_{\mathrm{J}}\right)$ with presence or absence (1 or 0$)$ data, Sørensen dissimilarity measure $\left(d_{\mathrm{S}}\right)$ with presence or absence $(1$ or 0$)$ data, Gower's modified dissimilarity measure $\left(d_{\mathrm{MG}}\right)$ with $\log _{10}(x+1)$-transformation for positive values, and $d_{\mathrm{BC}}$, the Bray-Curtis Wisconsin transformation. Down arrows indicate decreases since 1958.

Van Calster et al. 2007, McCune and Vellend 2013, Johnson et al. 2014). This suggests that community responses to environmental changes vary with context. Reviewing multiple studies, Vellend et al. (2013) found mixed evidence for plant diversity changes at local scales and no net change overall.

The increases in alpha and gamma diversity we found probably reflect succession following fire suppression. We can expect species richness to peak in midsuccessional communities, when species from both early- and middle-late successional stages coexist (Horn 1974). We observed pronounced succession at our sites, with conspicuous increases in canopy coverage, basal area per stem and per hectare, woody plant diversity, and relative abundance of woody species. Roughly half of the winners were shade-tolerant woody species, while most losers were shade-intolerant and herbaceous species. The high variation in species composition we observed among sites in 1958 may reflect that sites were still at early stages of succession. In 1958, these sites supported species from both southern prairie and northern hardwood forest communities (Habeck $1959 a, b)$. However, in 2012, prairie species were absent from almost all sites. Conversely, we observed high variation in species relative abundances among sites in 2012. In 2012, we found more species that were observed at only one or two sites, while the abundances of dominant species remained almost the same (Appendix A: Fig. A2). This may reflect the fact that sites in 2012 were in mid-succession. All these trends support the idea that succession following fire suppression has acted to drive shifts in species diversity and community composition in this system.

In contrast to our results, Brockway and Lewis (1997) and Peterson and Reich (2008) found that understory species diversity decreased after fire suppression. This may reflect differences either in the communities being studied or the time intervals involved (40 years postsuppression vs. $>60$ years in our study). Following fire suppression, understory species diversity may first decline with the local extinction of fire-adapted species. As succession proceeds, however, more shade-adapted species will colonize the site and increase in frequency. The outcome of these processes will depend on the time since fire suppression and the relative rates at which various species decline and colonize, leading to either higher or lower species diversity relative to the community before fire suppression.

We observed a strong pattern of biotic homogenization at these sites, as judged by declines in Shannon beta diversity, distances among sites in the NMDS ordina-
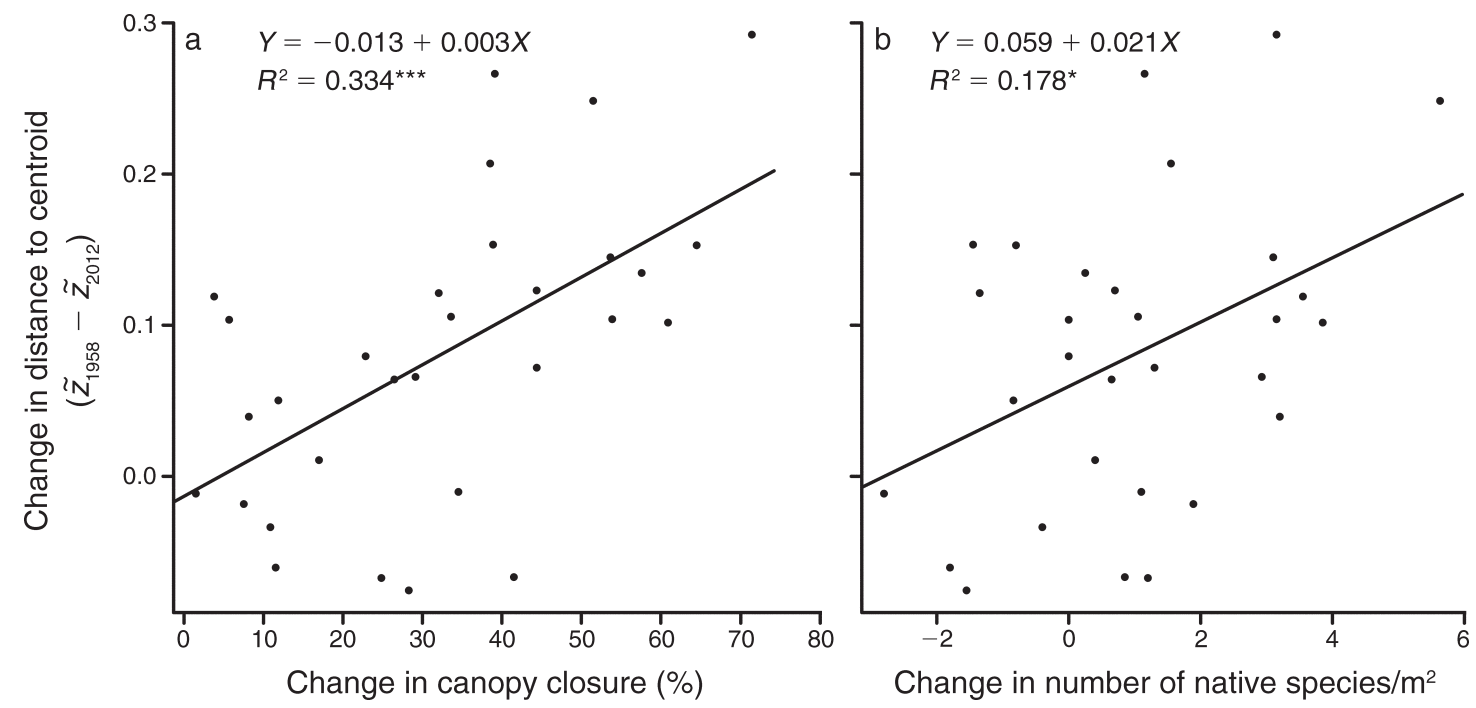

FIG. 5. Changes in distance from the multivariate space centroid over time using understory data $\left(\tilde{z}_{1958}-\tilde{z}_{2012}>0\right.$ suggests biotic homogenization) (a) increase with increases in canopy coverage $\left(\right.$ Cover $_{2012}-$ Cover $_{1958}$ ) and (b) increase with increases in number of native species at the $1-\mathrm{m}^{2}$ quadrat level $\left(S_{2012}-S_{1958}\right)$. Shown are the best-fit lines by ordinary least square linear regression: * $P<0.05 ; * * * P<0.001$. 
tion, and measures of multivariate dispersion. All longterm studies of forest community change in Wisconsin have found significant biotic homogenization (Rooney et al. 2004, Rogers et al. 2008, Johnson et al. 2014). However, the rate of homogenization in these sand plain communities in central Wisconsin is triple that found in northern and southern upland forests in Wisconsin ( $24.1 \%$ vs. $8.7 \%$ and $7.1 \%$, respectively), and only slightly lower than what was found in floodplain forests (24.1\% vs. $30.4 \%$ ). This may reflect the fact that both pine barrens and floodplain forests are highly dynamic systems adapted to recurrent disturbance.

In our study, the increases in canopy cover resulting from fire suppression acted to drive biotic homogenization. Our functional trait analysis further supported this idea in that the closing canopies favored shade-tolerant species, which tended to displace more light-demanding prairie species. Biotic homogenization caused by succession after fire suppression was also observed in other systems. For example, Velle et al. (2014) found coastal heathlands were becoming more similar with ongoing post-fire succession. The indicator species analysis showed that most losers occurred at only a few sites while most winners occurred commonly across sites (Fig. 6). Similar trends were apparent in parallel analyses of community change in the upland forests of northern and southern Wisconsin (Wiegmann and Waller 2006, Rogers et al. 2008, 2009). They are also consistent with the patterns of species loss expected under classic metapopulation models, like the coresatellite hypothesis (e.g., Gotelli and Simberloff 1987). Increases in species that occur at over half the sites will necessarily increase biotic homogenization (Rooney et al. 2007), perhaps explaining why big increases in biotic homogenization occurred even as local diversity increased.

In this system, increases in exotic species did not contribute to biotic homogenization. Olden et al. (2004) proposed that invading exotic species play a key role in biotic homogenization, as a small set of exotic species often invade many different communities. Their actual effect, however, depends on their incidence and abundance (McKinney 2004). Gaining a species that only occurs in few other sites will contribute to biotic differentiation (Rooney et al. 2007). This study, and several others documenting biotic homogenization, found no evidence that invasions by exotic species are driving this process (Rogers et al. 2008, McCune and Vellend 2013, Johnson et al. 2014). Instead, these studies mostly found that shifts in native species distribution and abundance drive biotic homogenization (Keith et al. 2009, Naaf and Wulf 2010, McCune and Vellend 2013, Johnson et al. 2014). In our study, Habeck only found two exotic species in 1958 while we found just 12 in 2012, with quadrat frequencies remaining low across both periods. Among the 29 winners, only two were exotic (Rhamnus frangula, Rumex acetosella). As a result, homogenization reflected changes in native

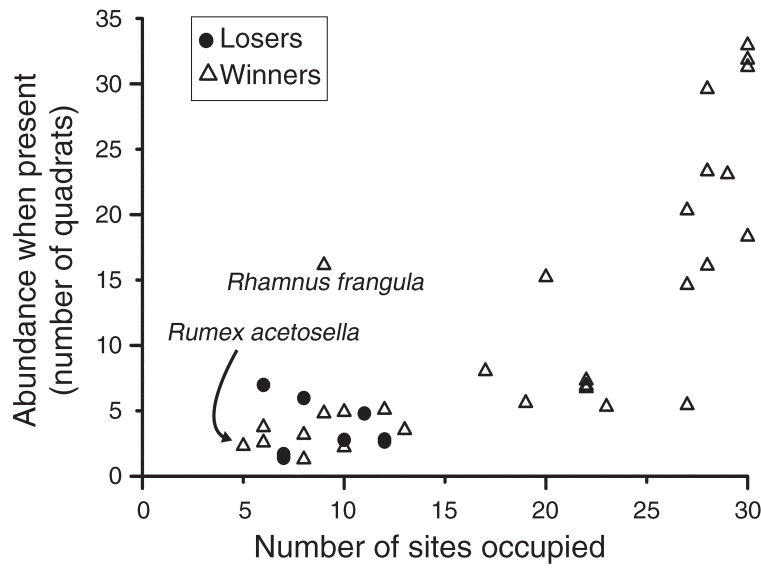

FIG. 6. Site frequency and mean quadrat frequency over sites where understory species were observed for losers and winners (according to indicator species analysis). Data for losers are from the 1958 data set, while data for winners are from the 2012 data set. The two labeled species were exotic species while all other species were native species.

species rather than exotic species. Even with substantial increases in exotic species richness, McCune and Vellend (2013) found no relationship between exotic species and biotic homogenization. All of these studies suggest that whether exotic species cause biotic homogenization or not depends on how frequently they occur.

Climate change may also contribute to the biotic homogenization we observed. Most of our sites occurred in the southern half of the tension zone in 1958. Wisconsin's tension zone runs diagonally, northwest to southeast (Fig.1) and reflects the positions of climatic isolines including temperature, precipitation, and snow depth. Plant communities located in tension zones are expected to respond quickly and dramatically to changes in climate and environmental conditions (Allen and Breshears 1998). As a result, sites in 1958 may have experienced very different climatic conditions and, thus, have different species composition than in 2012. Over the past 50 years, the tension zone has moved north as precipitation and temperatures have increased (Kucharik et al. 2010, WICCI 2011). This may have left most of our sites behind, with sites in 2012 experiencing different, and more consistent, climatic conditions than in 1958, leading to more similar species composition. Indeed, the coefficient of variation of daily precipitation and daily minimum temperature at these sites has decreased appreciably (from 0.027 to 0.015 and from 1.189 to 0.135 , respectively, unpublished data). This decrease in climate heterogeneity among our sites may have contributed to the decline in beta diversity that we observed.

In conclusion, plant communities in the western CSP have undergone strong biotic homogenization over the last 54 years even as they have gained species richness at the local and regional scales. Increases in native species 
and canopy cover account for most of the biotic homogenization we observed, while initial invasions by exotic species did not promote biotic homogenization. These strong trends support the idea that succession following fire suppression is driving most of these changes. Our findings highlight the importance of fire in the maintenance of pine barrens and demonstrate the utility of replicated, long-interval resurvey data for inferring the processes involved in reassembling plant communities following a major shift in disturbance regimes.

\section{ACKNOWLEDGMENTS}

We are indebted to James R. Habeck for his efforts of sampling and data archiving in 1958. This work would have been impossible without his baseline data. We thank public and private landowners of Wisconsin for allowing access to their properties. We also thank Marian Lea and Amelia Krug for their able field skills. T. Cochrane of the University of Wisconsin Herbarium and Bil Alverson assisted with the plant identifications. Grégory Sonnier, Sara Souther, Bil Alverson, Vigdis Vandvik, and one anonymous reviewer provided useful comments on the manuscript. Crucial financial support for this project came from the NSF (DEB 1046355). We are also grateful for financial support provided by the Flora Aeterna and Davis Research funds of the University of Wisconsin Department of Botany.

\section{Literature Cited}

Allen, C. D., and D. D. Breshears. 1998. Drought-induced shift of a forest-woodland ecotone: rapid landscape response to climate variation. Proceedings of the National Academy of Sciences USA 95:14839-14842.

Amatangelo, K., S. Johnson, D. Rogers, and D. Waller. 2014. Trait-environment relationships remain strong despite fifty years of trait compositional change in Wisconsin forests. Ecology 95:1780-1791.

Anderson, M. J., K. E. Ellingsen, and B. H. McArdle. 2006. Multivariate dispersion as a measure of beta diversity. Ecology Letters 9:683-693.

Barlow, J., and C. A. Peres. 2008. Fire-mediated dieback and compositional cascade in an Amazonian forest. Philosophical Transactions of the Royal Society B 363:1787-1794.

Bond, W. J., and J. E. Keeley. 2005. Fire as a global herbivore: the ecology and evolution of flammable ecosystems. Trends in Ecology and Evolution 20:387-394.

Bond, W. J., F. I. Woodward, and G. F. Midgley. 2005. The global distribution of ecosystems in a world without fire. New Phytologist 165:525-538.

Bordner, J. 1934. Land Economic Inventory of the State of Wisconsin, Juneau County. Madison, Wisconsin, USA.

Bowman, D. M. J. S., et al. 2009. Fire in the earth system. Science 324:481-484.

Brockway, D. G., and C. E. Lewis. 1997. Long-term effects of dormant-season prescribed fire on plant community diversity, structure and productivity in a longleaf pine wiregrass ecosystem. Forest Ecology and Management 96:167-183.

Christensen, R. H. B. 2013. ordinal: regression models for ordinal data. R package version 2010.12-15. http://www. cran.r-project.org/package $=$ ordinal/

Collins, B. M., R. G. Everett, and S. L. Stephens. 2011. Impacts of fire exclusion and recent managed fire on forest structure in old growth Sierra Nevada mixed-conifer forests. Ecosphere 2. http://dx.doi.org/10.1890/ES11-00026.1

Cottam, G., and J. T. Curtis. 1956. The use of distance measures in phytosociological sampling. Ecology 37:451460 .
Curtis, J. T. 1959. The vegetation of Wisconsin. University of Wisconsin Press, Madison, Wisconsin, USA.

Damschen, E. I., S. Harrison, and J. B. Grace. 2010. Climate change effects on an endemic-rich edaphic flora: resurveying Robert H. Whittaker's Siskiyou sites (Oregon, USA). Ecology 91:3609-3619.

Debano, L. F., and C. E. Conrad. 1978. The effect of fire on nutrients in a chaparral ecosystem. Ecology 59:489-497.

Dolanc, C. R., H. D. Safford, S. Z. Dobrowski, and J. H. Thorne. 2014. Twentieth century shifts in abundance and composition of vegetation types of the Sierra Nevada, CA, US. Applied Vegetation Science 17:442-455.

Dufrene, M., and P. Legendre. 1997. Species assemblages and indicator species: The need for a flexible asymmetrical approach. Ecological Monographs 67:345-366.

Gilliam, F. S., and W. J. Platt. 1999. Effects of long-term fire exclusion on tree species composition and stand structure in an old-growth Pinus palustris (longleaf pine) forest. Plant Ecology 140:15-26.

Gotelli, N. J., and R. K. Colwell. 2001. Quantifying biodiversity: procedures and pitfalls in the measurement and comparison of species richness. Ecology Letters 4:379-391.

Gotelli, N. J., and D. Simberloff. 1987. The distribution and abundance of tallgrass prairie plants: a test of the coresatellite hypothesis. American Naturalist 130:18-35.

Habeck, J. 1959a. A phytosociological study of the upland forest communities in the central Wisconsin sand plain area. Wisconsin Academy of Science, Arts and Letters 48:31-48.

Habeck, J. R. 1959b. A vegetational study of the central Wisconsin winter deer range. Journal of Wildlife Management 23:273-278.

Horn, H. S. 1974. The ecology of secondary succession. Annual Review of Ecology and Systematics 5:25-37.

Johnson, S. E., E. L. Mudrak, and D. M. Waller. 2014. Local increases in diversity accompany community homogenization in floodplain forest understories. Journal of Vegetation Science 25:885-896.

Johnson, S. E., and D. M. Waller. 2012. Influence of dam regulation on 55-year canopy shifts in riparian forests. Canadian Journal of Forest Research 43:159-170.

Jost, L. 2007. Partitioning diversity into independent alpha and beta components. Ecology 88:2427-2439.

Keith, S. A., A. C. Newton, M. D. Morecroft, C. E. Bealey, and J. M. Bullock. 2009. Taxonomic homogenization of woodland plant communities over 70 years. Proceedings of the Royal Society B 276:3539-3544.

Knapp, E. E., C. N. Skinner, M. P. North, and B. L. Estes. 2013. Long-term overstory and understory change following logging and fire exclusion in a Sierra Nevada mixed-conifer forest. Forest Ecology and Management 310:903-914.

Kucharik, C. J., S. P. Serbin, S. Vavrus, E. J. Hopkins, and M. M. Motew. 2010. Patterns of climate change across Wisconsin from 1950 to 2006. Physical Geography 31:1-28.

Leach, M. K., and T. J. Givnish. 1996. Ecological determinants of species loss in remnant prairies. Science 273:1555-1558.

McCune, J. L., and M. Vellend. 2013. Gains in native species promote biotic homogenization over four decades in a human-dominated landscape. Journal of Ecology 101:15421551.

McKinney, M. L. 2004. Do exotics homogenize or differentiate communities? Roles of sampling and exotic species richness. Biological Invasions 6:495-504.

Naaf, T., and M. Wulf. 2010. Habitat specialists and generalists drive homogenization and differentiation of temperate forest plant communities at the regional scale. Biological Conservation 143:848-855.

Naeem, S., D. E. Bunker, and A. Hector. 2009. Biodiversity, ecosystem functioning, and human wellbeing: an ecological and economic perspective. Oxford University Press, New York, New York, USA. 
Nilsson, M.-C., and D. A. Wardle. 2005. Understory vegetation as a forest ecosystem driver: evidence from the northern Swedish boreal forest. Frontiers in Ecology and the Environment 3:421-428.

Nowacki, G. J., and M. D. Abrams. 2008. The demise of fire and "mesophication" of forests in the eastern United States. BioScience 58:123-138.

Oksanen, J., F. G. Blanchet, R. Kindt, P. Legendre, P. R. Minchin, R. B. O'Hara, G. L. Simpson, P. Solymos, M. H. H. Stevens, and H. Wagner. 2013. vegan: community ecology package. http://CRAN.R-project.org/ package $=$ vegan

Olden, J. D., N. LeRoy Poff, M. R. Douglas, M. E. Douglas, and K. D. Fausch. 2004. Ecological and evolutionary consequences of biotic homogenization. Trends in Ecology and Evolution 19:18-24.

Parsons, D. J., and S. H. DeBenedetti. 1979. Impact of fire suppression on a mixed-conifer forest. Forest Ecology and Management 2:21-33.

Peterson, D. W., and P. B. Reich. 2001. Prescribed fire in oak savanna: fire frequency effects on stand structure and dynamics. Ecological Applications 11:914-927.

Peterson, D. W., and P. B. Reich. 2008. Fire frequency and tree canopy structure influence plant species diversity in a forestgrassland ecotone. Plant Ecology 194:5-16.

R Core Team. 2013. R: A language and environment for statistical computing. R Foundation for Statistical Computing, Vienna, Austria. http://www.r-project.org

Roberts, D. W. 2013. labdsv: Ordination and multivariate analysis for ecology. http://cran.r-project.org/web/packages/ labdsv/index.html

Rogers, D. A., T. P. Rooney, T. J. Hawbaker, V. C. Radeloff, and D. M. Waller. 2009. Paying the extinction debt in southern Wisconsin forest understories. Conservation Biology 23:1497-1506.

Rogers, D. A., T. P. Rooney, D. Olson, and D. M. Waller. 2008. Shifts in southern Wisconsin forest canopy and understory richness, composition, and heterogeneity. Ecology 89:2482-2492.

Rooney, T. P., J. D. Olden, M. K. Leach, and D. A. Rogers. 2007. Biotic homogenization and conservation prioritization. Biological Conservation 134:447-450.

Rooney, T. P., S. M. Wiegmann, D. A. Rogers, and D. M. Waller. 2004. Biotic impoverishment and homogenization in unfragmented forest understory communities. Conservation Biology 18:787-798.
Sax, D. F., and S. D. Gaines. 2003. Species diversity: from global decreases to local increases. Trends in Ecology and Evolution 18:561-566.

Simard, A., and R. Blank. 1982. Fire history of a Michigan jack pine forest. Michigan Academician 1:59-71.

Sonnier, G., S. E. Johnson, K. L. Amatangelo, D. A. Rogers, and D. M. Waller. 2014. Is taxonomic homogenization linked to functional homogenization in temperate forests? Global Ecology and Biogeography 23:894-902.

Thomson, J. W. 1943. Plant succession on abandoned fields in the central Wisconsin sand plain area. Bulletin of the Torrey Botanical Club 70:34-41.

Van Calster, H., L. Baeten, A. De Schrijver, L. De Keersmaeker, J. E. Rogister, K. Verheyen, and M. Hermy. 2007. Management driven changes (1967-2005) in soil acidity and the understory plant community following conversion of a coppice-with-standards forest. Forest Ecology and Management 241:258-271.

Velle, L. G., L. S. Nilsen, A. Norderhaug, and V. Vandvik. 2014. Does prescribed burning result in biotic homogenization of coastal heathlands? Global Change Biology 20:14291440.

Vellend, M., L. Baeten, I. H. Myers-Smith, S. C. Elmendorf, R. Beauséjour, C. D. Brown, P. D. Frenne, K. Verheyen, and S. Wipf. 2013. Global meta-analysis reveals no net change in local-scale plant biodiversity over time. Proceedings of the National Academy of Sciences USA 110:19456-19459.

Veno, P. A. 1976. Successional relationships of five Florida plant communities. Ecology 57:498-508.

WICCI. 2011. Wisconsin's changing climate: impacts and adaptation. Technical report, Nelson Institute for Environmental Studies, University of Wisconsin and the Wisconsin Department of Natural Resources, Madison, Wisconsin, USA.

Wiegmann, S. M., and D. M. Waller. 2006. Fifty years of change in northern upland forest understories: identity and traits of "winner" and "loser" plant species. Biological Conservation 129:109-123.

Wisconsin Department of Natural Resources. 2014. The ecological landscapes of Wisconsin: an assessment of ecological resources and a guide to planning sustainable management. Chapter 10. Central sand plains ecological landscape. Wisconsin Department of Natural Resources, Madison, Wisconsin, USA.

Woinarski, J. C. Z., J. Risler, and L. Kean. 2004. Response of vegetation and vertebrate fauna to 23 years of fire exclusion in a tropical eucalyptus open forest, Northern Territory, Australia. Austral Ecology 29:156-176.

\section{Supplemental Material}

\section{Ecological Archives}

Appendix A is available online: http://dx.doi.org/10.1890/14-0893.1.sm 